OPEN ACCESS

Edited by: Maria Abian,

University of Zaragoza, Spain

Reviewed by:

Katiuska Alexandrino, University of the Americas, Ecuador Ernesto Salzano,

University of Bologna, Italy

*Correspondence:

Yankun Jiang

jykhust@hust.edu.cn

Specialty section:

This article was submitted to Advanced Clean Fuel Technologies,

a section of the journal Frontiers in Energy Research

Received: 10 November 2021 Accepted: 17 December 2021

Published: 19 January 2022

Citation:

Chen $Y$, Jiang $Y$, Wen $X$ and Liu $H$ (2022) An Investigation of the Kinetic Modeling and Ignition Delay Time of

Methanol-Syngas Fuel.

Front. Energy Res. 9:812522.

doi: 10.3389/fenrg.2021.812522

\section{An Investigation of the Kinetic Modeling and Ignition Delay Time of Methanol-Syngas Fuel}

\author{
Yexin Chen ${ }^{1}$, Yankun Jiang ${ }^{1,2 *}$ Xin Wen ${ }^{1}$ and Huimeng Liu ${ }^{1}$ \\ ${ }^{1}$ School of Energy and Power Engineering, Huazhong University of Science and Technology, Wuhan, China, ${ }^{2}$ State Key \\ Laboratory of Coal Combustion, Huazhong University of Science and Technology, Wuhan, China
}

The recycling of exhaust heat in internal combustion engines to dissociate the methanol, followed by its blending with methanol to produce engine fuel, is promising for improving the efficiency of engines, and reducing emissions. The kinetic model MEOHSYNGAS1.0 for the methanol-syngas fuel is proposed by reducing the detailed chemical kinetic model (Mech15.34). Shock tube experiments are conducted to measure the ignition delay time of methanol blended with dissociated methanol gas at different dissociated methanol ratios $(0,30,50$, and $100 \%)$. The model is validated by the experimental data of the present work and with data from the literature. The effects of the equivalence ratio, pressure, and dissociated methanol ratio on the ignition delay time are investigated through reaction path analysis and sensitivity analysis. When the dissociated methanol ratio does not surpass $50 \%$, the ignition delay time increases with the increase in the dissociated methanol ratio, which is more obvious in the low temperature range, and but decreases with the increase in temperature.

Keywords: methanol-syngas, dissociated methanol gas, kinetic modeling, ignition delay time, combustion

\section{INTRODUCTION}

Methanol is a promising fuel for internal combustion engines because it can be efficiently and cleanly burned (Verhelst et al., 2019). In addition, methanol is used as an energy carrier for transportation vehicles (Jaspers et al., 2021). Carbon neutrality can be achieved by capturing carbon dioxide $\left(\mathrm{CO}_{2}\right)$ to produce methanol with renewable energy (Borisut and Nuchitprasittichai, 2019). Methanol can be used in either the spark-ignition engine or the compression-ignition engine, burning either pure methanol directly or a blend of methanol with gasoline or diesel (Li et al., 2021). To improve the thermal efficiency of the engine, the method of blending methanol with dissociated methanol gas was proposed (Xie, 2016; Wen, 2018). Specifically, the methanol is vaporized by the exhaust heat of the internal combustion engine through a methanol dissociation device, and then dissociated using a catalyst to generate a mixture of hydrogen $\left(\mathrm{H}_{2}\right)$ and carbon monoxide $(\mathrm{CO})$ with a ratio of 2:1. The resulting syngas is added to the engine cylinder to improve combustion, as Figure $\mathbf{1}$ shows.

The thermal decomposition global reaction is

$$
\mathrm{CH}_{3} \mathrm{OH}=2 \mathrm{H}_{2}+\mathrm{CO},
$$

This method can not only recycle the exhaust heat, but also enable the engine to be closer to the constant volume cycle, and, thus, the thermal efficiency of the engine is improved (Ji et al., 2013). In addition, dissociated methanol gas is rich in hydrogen, and mixing hydrogen with a hydrocarbon fuel for combustion can increase the flame speed (Zhao et al., 2019), and extend the lean-burn limit 


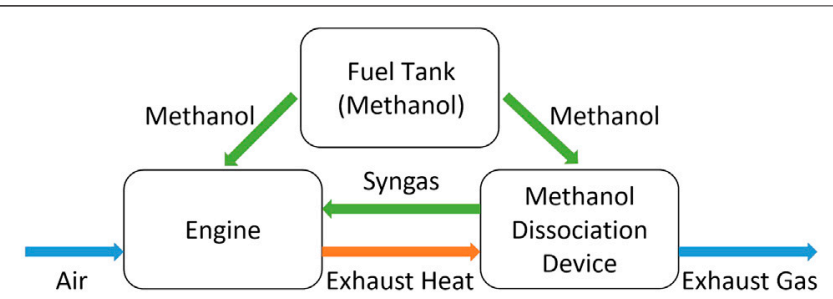

FIGURE 1 | Blending methanol and syngas as a fuel for the internal combustion engine.

(Jaimes et al., 2018). Lean combustion enables the fuel to burn completely, which further increases the thermal efficiency, and may reduce the emissions of CO (Liu and Dumitrescu, 2019). In addition, lean-burn can reduce the combustion temperature, thus reducing $\mathrm{NO}_{\mathrm{x}}$ emissions (Yao et al., 2014). Considering the research of Nguyen and Verhelst (2017), Gong et al. (2019), Zhang et al. (2014), and other scholars on the use of methanol blended with hydrogen as a fuel for internal combustion engines, as well as our previous research (Jiang et al., 2019), the results show that under suitable working conditions and parameters, blending methanol and dissociated methanol gas as a fuel can improve the efficiency and reduce emissions of internal combustion engines.

At present, there are very few direct studies on the kinetic modeling of methanol-syngas fuel where hydrogen $\left(\mathrm{H}_{2}\right)$ and carbon monoxide (CO) are mixed at a ratio of $2: 1$. This section will review the oxidation mechanism of methanol and syngas. Sun et al. (2007) constructed the oxidation mechanism of $\mathrm{CO} / \mathrm{H}_{2} /$ air, and the flame speed was measured by the constant-pressure spherical flame technique. Combined with previous ignition temperatures results, the mechanism proved to be accurate. Some of the mechanism parameters were determined by $a b$ initio calculations. Kalitan et al. (2007) studied the combustion characteristics of syngas by a shock tube with a temperature range of $809-1300 \mathrm{~K}$, a pressure of $1.0,2.5$, and $15.0 \mathrm{~atm}$, and an equivalence ratio of 0.5 . Thi et al. (2014) investigated the ignition delay time of syngas at different equivalence ratios by a shock tube at $870-1350 \mathrm{~K}$, a pressure $0.2,1.0$, and $2.0 \mathrm{MPa}$, and equivalence ratios of $0.3,1.0$, and 1.5 . Kéromnès et al. (2013) updated the kinetic model of the $\mathrm{H}_{2} / \mathrm{CO} / \mathrm{O}_{2} / \mathrm{N}_{2} / \mathrm{AR}$ system and verified the accuracy of the mechanism by various experiments including a shock tube, a rapid compression machine (RCM), a spherical bomb facility, etc. It had a pressure range of 1-70 bar, a temperature range of $914-2220 \mathrm{~K}$, and an equivalence ratio range of 0.1-4.0. Mansfield and Wooldridge (2014) studied the ignition characteristics of syngas at a low temperature with a RCM. The $\mathrm{H}_{2} / \mathrm{CO}$ mole ratio was 0.7 , the temperature range was $870-1150 \mathrm{~K}$, the pressure range was $3-15 \mathrm{~atm}$, and the equivalence ratios were 0.1 and 0.5 .

The mechanism of methanol oxidation proposed by Held and Dryer (1998) was verified by many experiments, in which the temperature range was $633-2050 \mathrm{~K}$, the pressure range was $0.26-20 \mathrm{~atm}$, and the equivalence ratio range was $0.05-2.6$. The experimental verification included a shock tube, a flow reactor, a burner-stabilized flame, a laminar premixed flame, etc. Although some radicals, such as $\mathrm{CH}$ and $\mathrm{CH}_{2}$, are neglected in this mechanism, it is consistent with the experimental data. $\mathrm{Li}$ et al. (2007) updated some of the reaction rate constants and thermodynamic data in the methanol oxidation process. According to the $\mathrm{H}_{2} / \mathrm{O}_{2} / \mathrm{CO} / \mathrm{HCO} / \mathrm{CH}_{2} \mathrm{O} / \mathrm{CH}_{3} / \mathrm{CH}_{4} / \mathrm{CH}_{2} \mathrm{OH} /$ $\mathrm{CH}_{3} \mathrm{O} / \mathrm{CH}_{3} \mathrm{OH}$ reaction pathway, the mechanism of the methanol oxidation was constructed. The mechanism proposed by $\mathrm{Li}$ et al. (2007) was verified by experimental results using a shock tube, a laminar premixed flame, a burner-stabilized flame, and a flow reactor, where the temperature range was $300-2200 \mathrm{~K}$, the pressure range was 1-20 atm, and the equivalence ratio range was 0.05-6.0. Liao et al. (2011) simplified the methanol mechanism proposed by Held and Dryer (1998), from 22 species and 89 reactions to 17 species and 40 elementary reactions. The mechanism was verified by ignition delay time, premixed laminar flame speeds, and the radicals in static reactors and flow reactors. The temperature ranged from 823 to $2180 \mathrm{~K}$, the pressure ranged from 0.005 to 2.0 $\mathrm{MPa}$, and the equivalence ratio ranged from 0.2 to 2.6. The error between the simulation and experimental results was acceptable. Pinzón et al. (2019) undertook a shock tube experiment for methanol oxidation and measured water timehistory profiles. The experimental temperature range was $940-1540 \mathrm{~K}$, the pressure was 1.3 and $14.9 \mathrm{~atm}$, and the equivalence ratios were $0.5,1.0$, and 2.0. The methanol oxidation process was analyzed by the rate of production (ROP) and sensitivity analysis, focusing on the effect on water production. The error between the simulation and experimental data was analyzed. Christensen et al. (2016) updated the Konnov mechanism, version 0.6 (Konnov, 2009). According to the latest theoretical research and experimental results, Christensen et al. (2016) systematically updated the rate constants and compared the simulation results with the experimental results of the shock tube, flow reactors, burner stabilized flame, and freely propagating flames. The results indicate that the new mechanism shows an obvious improvement in predicting the flame propagation speed of methanol.

Burke et al. (2016) summarized the previous studies on the mechanism of methanol oxidation and, based on new experimental data, presented the detailed kinetic model of methanol oxidation Mech15.34, and verified the new mechanism by the experimental results and previous data. Its verification methods include a shock tube, rapid compression machine, and jet-stirred reactor under a pressure range of $1-50 \mathrm{~atm}$, a temperature range of $800-1650 \mathrm{~K}$, and an equivalence ratio range of $0.2-2.0$. In addition, the simulation of the laminar premixed flame speed was also verified by previous experimental data (Vancoillie et al., 2012). This mechanism is a detailed and well-validated mechanism of methanol oxidation, but it contains 173 components and 1,011 elementary reactions, and is not suitable for the three-dimensional simulation of combustion in internal combustion engines under the current computational conditions. Aramcomech 3.0 (Zhou et al., 2018) is a detailed mechanism for the oxidation of hydrocarbon fuels, based on 1,3-butadiene, including $\mathrm{CH}_{3} \mathrm{OH}$. It was verified by a shock tube, RCM, and laminar flame speed. It contains 581 components and 3,037 elementary reactions, so it needs to be 


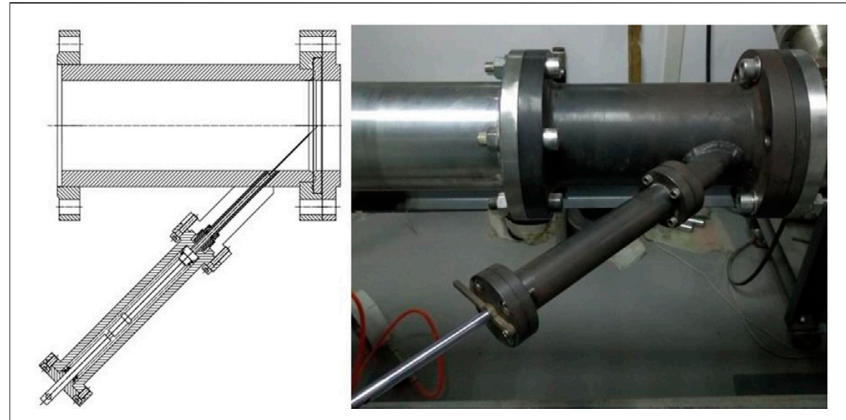

FIGURE 2 | Polyethylene terephthalate (PET) diaphragm is burst by a built-in spring needle to produce a shock wave.

simplified for the application in the methanol-syngas engine. Zhang and Zhang (2019) constructed the methanol-based toluene reference fuel mechanism, which has a high accuracy in the temperature range of 300-2500 $\mathrm{K}$, and an equivalence ratio range of $0.375-2.0$, and contains the submechanisms of methanol. Pichler and Nilsson (2020) analyzed the oxidation pathway of small alcohol in the internal combustion engine, and proposed a simplified mechanism of methanol, ethanol, and n-propanol. The mechanism is based on the equivalence ratio range of $0.7-1.4$, pressure range of 1-40 atm, temperature range of 700-1700 K, and their errors are within 5\% for the ignition delay times, laminar burning velocity, and extinction strain rate (Pichler and Nilsson, 2018).

In summary, the current research on the combustion kinetic modeling of the methanol-syngas mixture mainly focuses on syngas and methanol. There is no specific study on the dissociated methanol gas and methanol-dissociated methanol gas, and there is also a lack of experimental data on the mixture of methanol and dissociated methanol gas. In addition, the most recent comprehensive methanol mechanism that covers the interactions among $\mathrm{CH}_{3} \mathrm{OH}, \mathrm{CO}, \mathrm{H}_{2}$, and their intermediate species was proposed by Burke et al. (2016), and contains 173 species and 1,011 elementary reactions. It is too large for a threedimensional simulation of the combustion in internal combustion engines under the current computational conditions. In this study, the combustion characteristics of dissociated methanol gas and methanol blended with the dissociated methanol gas are analyzed, and a kinetic model, MEOHSYNGAS1.0, for the methanol-syngas fuel is proposed, and verified experimentally.

\section{METHODOLOGY}

\section{Shock Tube Experiments}

The shock tube used in this research was validated using various studies and the results were similar to those of other research institutions. Part of the research on fuel ignition delay times has been published (Liu et al., 2019). The shock tube used in this study was $12 \mathrm{~m}$ in total, of which the high-pressure section was $4 \mathrm{~m}$, the low-pressure section was $5 \mathrm{~m}$, and the inner diameter was $100 \mathrm{~mm}$. The driving section and the driven section were separated by a polyethylene terephthalate (PET) diaphragm. Considering the reliability and repeatability, the PET diaphragm was burst by a built-in spring needle to produce a shock wave, which is shown in Figure 2.

The mixing tank was first degassed and purged with Ar, followed by degassing again to remove the residual gas. The pressure in a $300 \mathrm{~L}$ mixing tank was first reduced below $3,000 \mathrm{~Pa}$ using a TRIVAC D40T vacuum pump and then below $1 \mathrm{~Pa}$ using a Ruwauvac 501 pump. The fuel, oxidant, and dilute gas were added. Finally, the mixture was left for more than $12 \mathrm{~h}$ to ensure complete mixing. For the methanol, it was necessary to first vacuum the tank and then inject the methanol so it vaporizes. Following this, the other gases were added. The fuels and gases used in the experiment, including $\mathrm{CH}_{3} \mathrm{OH}, \mathrm{H}_{2}, \mathrm{CO}, \mathrm{O}_{2}, \mathrm{Ar}, \mathrm{He}$, $\mathrm{N}_{2}$, had a purity of $\geq 99.9 \%$. The compositions of the mixtures used in the experiment are given in Table 1. The dissociated ratio is used to define the composition of the methanol-syngas blended fuel, which is the percentage of methanol dissociated to $\mathrm{H}_{2}$ and $\mathrm{CO}$ in the blended fuel. The dissociated methanol gas had a mole fraction of $67 \% \mathrm{H}_{2}$ and $33 \% \mathrm{CO}$. To determine the interaction between the methanol and syngas, the experimental pressure was set at $1.6 \mathrm{~atm}$.

Five PCB 111A24 piezoelectric pressure transducers were uniformly distributed near the end wall of the driven segment, between which the distance was $20 \mathrm{~cm}$. The nearest pressure transducer was $0.2 \mathrm{~cm}$ from the end wall to obtain a shock velocity. A Kistler 603B1 piezoelectric pressure transducer was also used to measure the pressure, which was $0.2 \mathrm{~cm}$ from the end wall. Finally, the temperature was calculated by the program Gaseq (Moley, 2003). The experimental bench was equipped with a band-pass filter with a wavelength of $307 \pm 10 \mathrm{~nm}$, which was connected to the photomultiplier through a QP600-2-SR fiber with a length of $2 \mathrm{~m}$ and a diameter of $0.6 \mathrm{~mm}$. All optical and pressure signals were converted into digital signals with an amplifier and exported. The ignition delay time was identified based on the pressure.

\section{Numerical Model}

A homogeneous 0-D reactor model was used to simulate the chemical reactions in the shock tube for the combustion study. The equations used to calculate the ignition delay time include the mass conservation equations, gas-phase species equations, gas energy equations, and gas equation of state. The simulation was conducted with the software ANSYS Chemkin.

The chemical rate of the fuel oxidation was calculated based on the Arrhenius equation. The rate constants of each elementary reaction are expressed as

$$
k=A T^{b} \exp \left(\frac{-E}{R T}\right),
$$

where $k$ is the reaction rate constant, $A$ is the pre-exponential factor, $T$ is the temperature, $b$ is the temperature exponent, $E$ is the activation energy, and $R$ is the gas constant.

Since the MEOHSYNGAS1.0 model needs to reflect the oxidation processes of $\mathrm{CH}_{3} \mathrm{OH}, \mathrm{H}_{2}$, and $\mathrm{CO}$, as well as the interactions among them and the intermediates, a comprehensive mechanism incorporating all these 
TABLE 1 | Mixture composition for the shock tube experiments.

\begin{tabular}{|c|c|c|c|c|c|c|c|}
\hline Mixture & $\mathrm{CH}_{3} \mathrm{OH}(\%)$ & $\mathrm{H}_{2}(\%)$ & CO (\%) & $\mathrm{O}_{2}(\%)$ & $\operatorname{Ar}(\%)$ & $\varphi$ & Dissociated ratio $(\%$ \\
\hline 1 & 4.0 & 0 & 0 & 6.0 & 90 & 1.0 & 0 \\
\hline 2 & 2.25 & 1.94 & 0.97 & 4.84 & 90 & 1.0 & 30 \\
\hline 3 & 1.42 & 2.86 & 1.43 & 4.29 & 90 & 1.0 & 50 \\
\hline 4 & 0 & 4.45 & 2.22 & 3.33 & 90 & 1.0 & 100 \\
\hline 5 & 0 & 3.64 & 1.82 & 4.54 & 90 & 0.6 & 100 \\
\hline
\end{tabular}

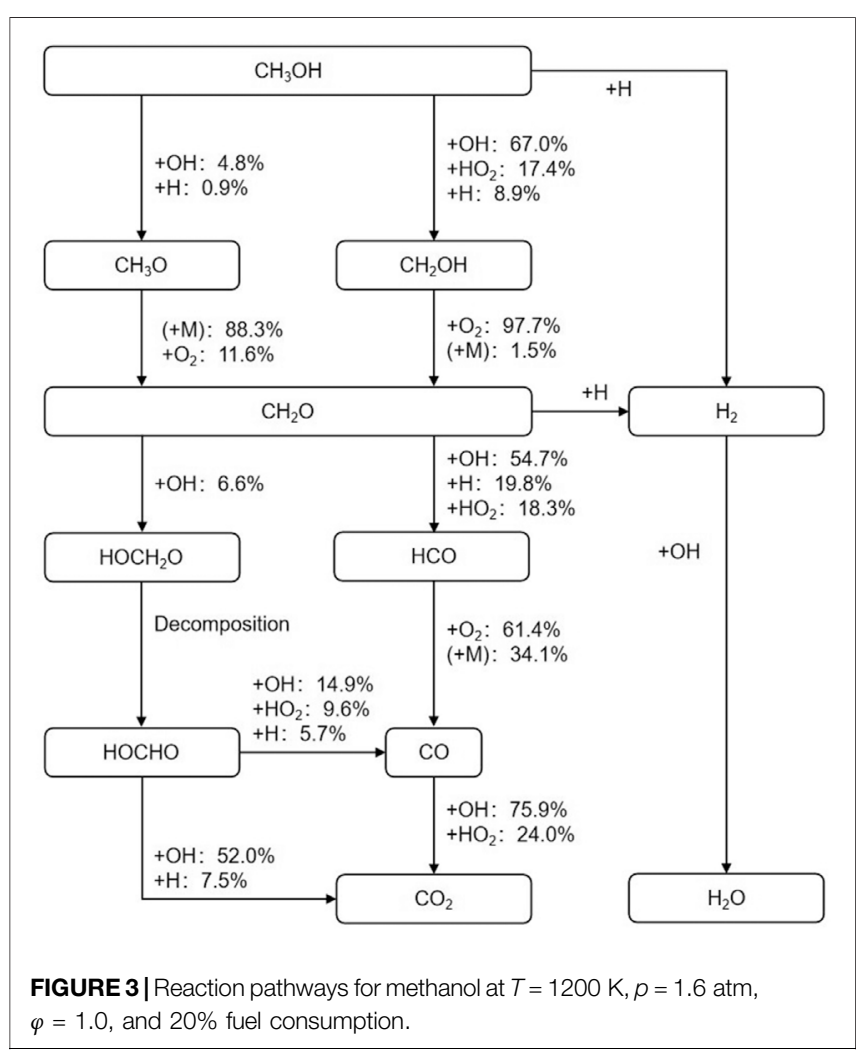

elementary reactions was selected at the beginning. Based on the Mech15.34 model proposed by Burke et al. (2016), mechanism reduction methods of directed relation graph with error propagation (Pepiot-Desjardins and Pitsch, 2008), and a full species sensitivity analysis (Turányi, 1997) were applied. The initial working condition range covers a pressure of 1-50 atm, a temperature of $800-1650 \mathrm{~K}$, an equivalence ratio $(\varphi)$ of $0.5-2.0$, and a dissociated methanol ratio of $0-50 \%$. As a result, the MEOHSYNGAS1.0 mechanism is able to predict the interaction among $\mathrm{CH}_{3} \mathrm{OH}, \mathrm{H}_{2}, \mathrm{CO}$, and the intermediates.

\section{Sensitivity Analysis}

Sensitivity analysis was performed to investigate the level of significance of a certain elementary reaction to the chemical reaction. The influence of the elementary reaction on the ignition delay time was evaluated by the sensitivity coefficient

$$
S_{i}=\frac{\tau_{2 k i}-\tau_{(1 / 2) k i}}{\tau_{k i}}
$$

where $S_{i}$ is the sensitivity coefficient, $\tau_{2 \mathrm{ki}}$ is the ignition time when the rate constant of the certain elementary reaction increases by two folds, $\tau_{(1 / 2) \text { ki }}$ is the ignition time when the rate constant of the certain elementary reaction decreases by half, and $\tau_{\mathrm{ki}}$ is the original ignition delay time of the certain elementary reaction.

The normalized sensitivity coefficient was obtained by

$$
S_{i, \text { normalized }}=\frac{S_{i}}{S_{i, \max }},
$$

where $S_{i \text {,normalized }}$ is the normalized sensitivity coefficient, $S_{i}$ is the sensitivity coefficient, and $S_{i, \max }$ is the maximum sensitivity coefficient among all elementary reactions in a specific condition. A positive sensitivity coefficient means that the elementary reaction inhibits the reactivity, while a negative sensitivity coefficient means that the elementary reaction promotes the reactivity.

\section{FUEL REACTION PATH ANALYSIS}

Figure 3 shows the reaction pathways of the methanol fuel. The initial reaction conditions were a temperature of $1200 \mathrm{~K}$, a pressure of $1.6 \mathrm{~atm}$, and an equivalence ratio of 1.0. The analyses were performed at the time when $20 \%$ of the methanol had been consumed. The percentage indicates the amount of a species consumed in the reaction, as a proportion of the total consumption of the substance at this time.

Methanol first undergoes a dehydrogenation reaction, mainly by the reaction between methyl and radicals such as $\mathrm{OH}, \mathrm{HO}_{2}$, and $\mathrm{H}$ to form $\mathrm{CH}_{2} \mathrm{OH}$. Moreover, a small amount of the reaction consists of the removal of hydrogen on the hydroxyl through $\mathrm{OH}, \mathrm{H}$ to produce $\mathrm{CH}_{3} \mathrm{O}$. Meanwhile, $\mathrm{H}_{2}$ is produced by the dehydrogenation reaction of methanol. $\mathrm{CH}_{2} \mathrm{OH}$ mainly reacts with $\mathrm{O}_{2}$ and also collides with a third body $\mathrm{M}$ to form $\mathrm{CH}_{2} \mathrm{O}$, while $\mathrm{CH}_{3} \mathrm{O}$ mainly collides with the $\mathrm{M}$, and also reacts with $\mathrm{O}_{2}$ to form $\mathrm{CH}_{2} \mathrm{O} . \mathrm{CH}_{2} \mathrm{O}$ is an important intermediate product in the process of methanol oxidation. It may become a pollutant in the combustion process of an internal combustion engine and be finally released into the atmosphere.

The main oxidation path of $\mathrm{CH}_{2} \mathrm{O}$ is to produce $\mathrm{HCO}$ by reacting with $\mathrm{OH}, \mathrm{H}, \mathrm{HO}_{2}$, and other radicals. $\mathrm{HCO}$ then reacts with $\mathrm{O}_{2}$ or collides with the $\mathrm{M}$ to generate $\mathrm{CO} . \mathrm{H}_{2}$ is also produced in the $\mathrm{CH}_{2} \mathrm{O}$ dehydrogenation reaction. The other reaction path of $\mathrm{CH}_{2} \mathrm{O}$ is to react with $\mathrm{OH}$ to form $\mathrm{HOCH}_{2} \mathrm{O}$, which subsequently decomposes into $\mathrm{HOCHO}$. HOCHO mainly reacts with $\mathrm{OH}$ or $\mathrm{H}$ to form $\mathrm{CO}_{2}$ and partially reacts with $\mathrm{OH}$, $\mathrm{HO}_{2}$, and $\mathrm{H}$ to form $\mathrm{CO}$. 


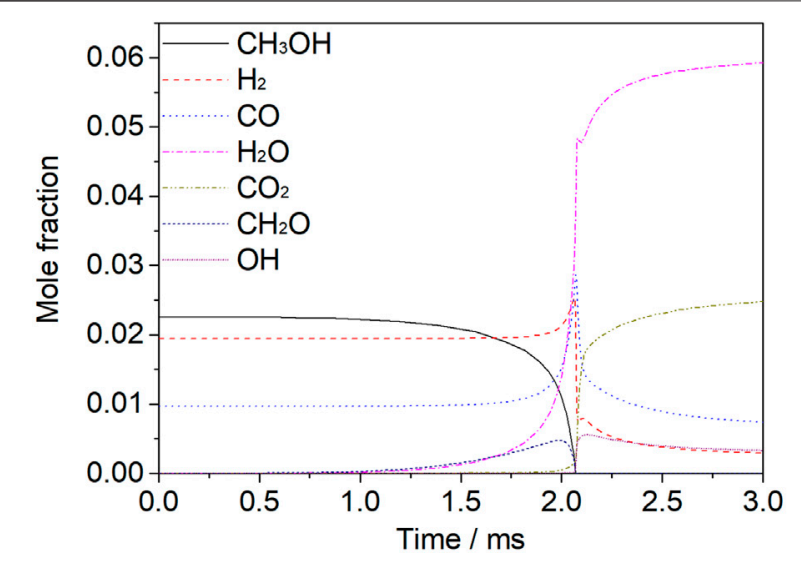

FIGURE 4 | Mole fraction analysis of species for a mixture of $30 \%$ dissociated methanol (Mixture 2) at $T=1200 \mathrm{~K}, p=1.6 \mathrm{~atm}, \varphi=1.0$, and $\operatorname{Ar}=0.9$.

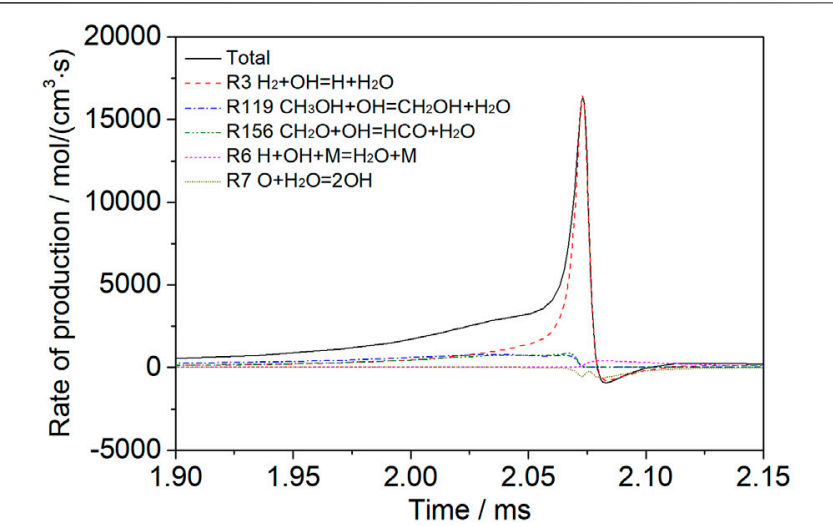

FIGURE 6 | Analysis of the $\mathrm{H}_{2} \mathrm{O}$ rate of production for a mixture of $30 \%$ dissociated methanol (Mixture 2) at $T=1200 \mathrm{~K}, p=1.6 \mathrm{~atm}, \varphi=1.0$, and $\operatorname{Ar}=0.9$.
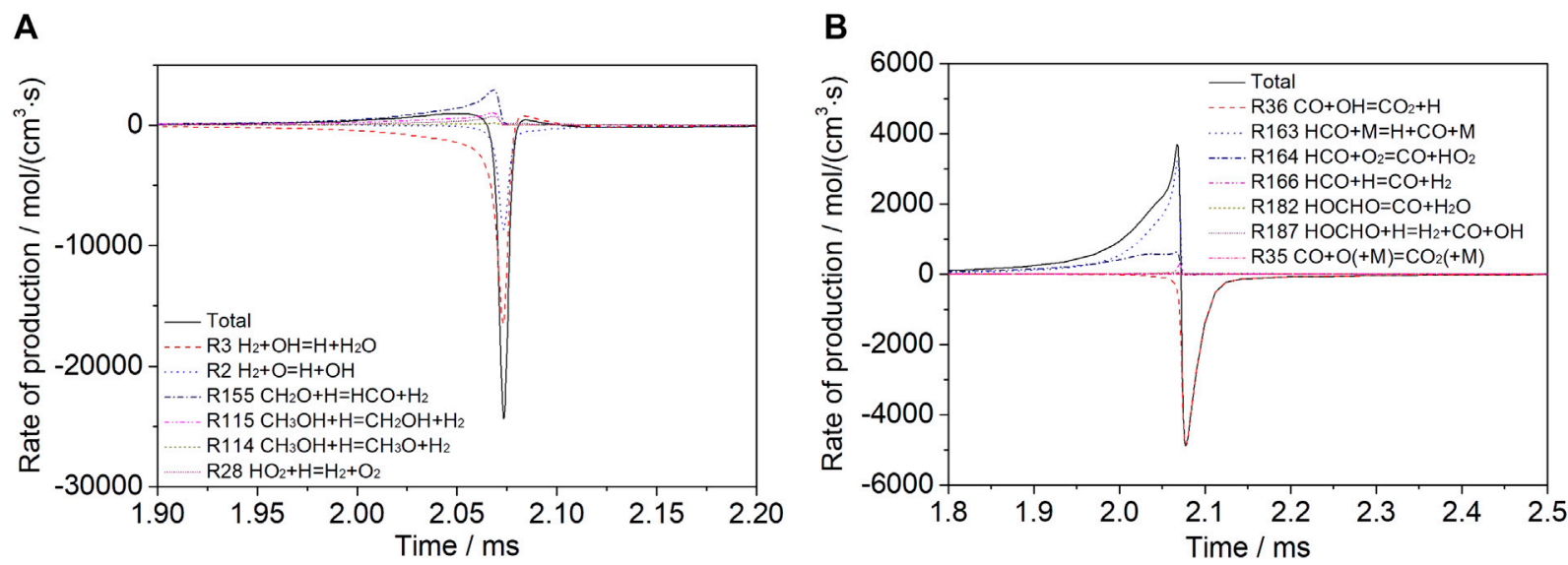

FIGURE 5 | Rate of production analysis for a mixture of 30\% dissociated methanol (Mixture 2) at $T=1200 \mathrm{~K}, p=1.6$ atm, $\varphi=1.0$, and $\mathrm{Ar}=0.9$ for $(\mathbf{A}) \mathrm{H}_{2}$ and (B) CO.

The main way that $\mathrm{CO}$ is oxidized to $\mathrm{CO}_{2}$ is by reacting with $\mathrm{OH}$ and $\mathrm{HO}_{2}$, though the amount of $\mathrm{CO}$ is very small at this time, because when the methanol consumption ratio is $20 \%$, a large number of hydrocarbons are still in the process of producing and consuming $\mathrm{CH}_{2} \mathrm{O}$.

At this stage, a small amount of $\mathrm{H}_{2} \mathrm{O}$ is generated, which mainly originates from the reaction of $\mathrm{OH}$ with $\mathrm{CH}_{3} \mathrm{OH}$ and $\mathrm{CH}_{2} \mathrm{O}$, respectively. In addition, $\mathrm{CH}_{3} \mathrm{OH}$ and $\mathrm{CH}_{2} \mathrm{O}$ react with $\mathrm{H}$ to form $\mathrm{H}_{2}$. The oxidation of $\mathrm{H}_{2}$ was the main source of water in the later stage of the reaction.

Figure 4 shows the variation of the mole fraction of different species with time at $1200 \mathrm{~K}, 1.6 \mathrm{~atm}$, a $30 \%$ dissociated ratio (Mixture 2), and an equivalence ratio of 1.0. The reaction time signifies the reaction process. At the initial stage, before the peak of the hydrogen fraction, the main reaction is dehydrogenation, and so the fraction of methanol gradually decreases with time. The oxidation of hydrocarbon fuels follows the path of $\mathrm{CH}_{3} \mathrm{OH}-$ $\mathrm{CH}_{2} \mathrm{O}-\mathrm{CO}$. Before $2 \mathrm{~ms}, \mathrm{CH}_{2} \mathrm{O}$ consumption was less than $\mathrm{CH}_{2} \mathrm{O}$ production, so $\mathrm{CH}_{2} \mathrm{O}$ increased. $\mathrm{CO}$ was mainly produced by the reaction between $\mathrm{HCO}$ and $\mathrm{O}_{2}$ and the collision between $\mathrm{HCO}$ and $\mathrm{M}$. The oxidation of $\mathrm{CO}$ to $\mathrm{CO}_{2}$ was not carried out on a large scale, so the increase rate of $\mathrm{CO}_{2}$ was slow. At this stage, both $\mathrm{CH}_{3} \mathrm{OH}$ and $\mathrm{CH}_{2} \mathrm{O}$ undergo dehydrogenation. They react with $\mathrm{H}$ to form $\mathrm{H}_{2}$, and with $\mathrm{OH}$ to form $\mathrm{H}_{2} \mathrm{O}$. At this stage, the production of $\mathrm{H}_{2}$ is more than the consumption of $\mathrm{H}_{2}$, and so $\mathrm{H}_{2}$ increases. The main sources of $\mathrm{H}_{2} \mathrm{O}$ are the reaction of $\mathrm{OH}$ with $\mathrm{H}_{2}, \mathrm{CH}_{3} \mathrm{OH}$, and $\mathrm{CH}_{2} \mathrm{O}$ respectively.

Figure 5 shows the rate of production of $\mathrm{H}_{2}$ and $\mathrm{CO}$ for a mixture of $30 \%$ dissociated methanol (Mixture 2) at $T=1200 \mathrm{~K}$, $p=1.6 \mathrm{~atm}, \varphi=1.0$, and $\mathrm{Ar}=0.9$. When the reaction reaches a certain point, after the peak of $\mathrm{H}_{2}$, the temperature rises, the radical $\mathrm{OH}$ is accumulated, and the chain branching reaction increases the oxidation rate rapidly. The reaction rate is further increased by the increasing temperature and the chain branching reaction; therefore, hydrogen is consumed rapidly. Before $\mathrm{H}_{2}$ peaks, $\mathrm{CO}$ increases because of the continuous formation, and 


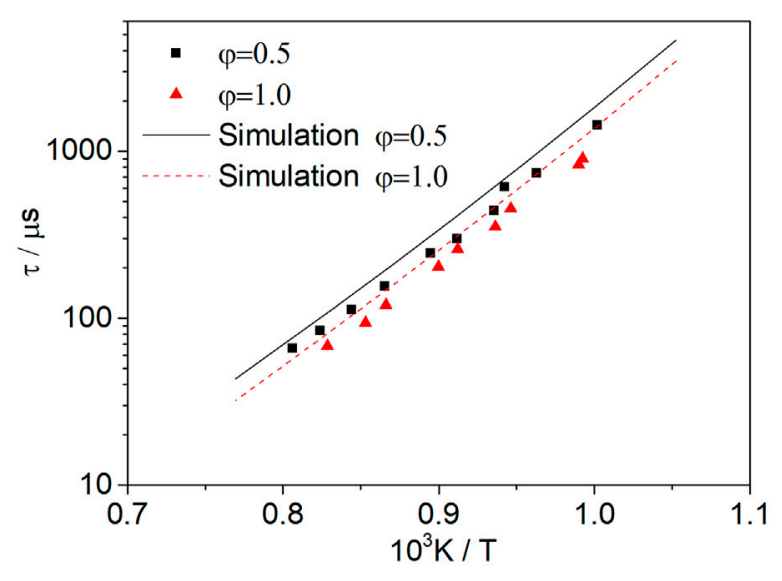

FIGURE 7 | Influence of the equivalence ratio on mixtures of methanol at $20 \mathrm{~atm}$. The symbols represent the experimental data from Burke et al. (2016).

when the production of $\mathrm{CH}_{3} \mathrm{OH}$ and $\mathrm{CH}_{2} \mathrm{O}$ is almost complete, $\mathrm{CO}$ begins to be consumed rapidly, mainly by the reaction between $\mathrm{CO}$ and $\mathrm{OH}$.

Figure 6 shows the $\mathrm{H}_{2} \mathrm{O}$ rate of production analysis for a mixture of $30 \%$ dissociated methanol (Mixture 2) at $T=1200 \mathrm{~K}$, $p=1.6 \mathrm{~atm}, \varphi=1.0$, and $\mathrm{Ar}=0.9$. In the early stage of the reaction, the main sources of water production are the dehydrogenation of $\mathrm{CH}_{3} \mathrm{OH}$, the dehydrogenation of $\mathrm{CH}_{2} \mathrm{O}$, and the reaction between $\mathrm{H}_{2}$ and $\mathrm{OH}$. In the later stage, the main source of water is the reaction of $\mathrm{H}_{2}$ with $\mathrm{OH}$.

According to the oxidation process of methanol, hydrogen, carbon monoxide, and other main intermediate species, the important elementary reactions can be determined. A reduced mechanism consisting of 28 species and 146 elementary reactions was constructed and named MEOHSYNGAS1.0.

\section{RESULTS AND DISCUSSION}

This section analyzes the effect of equivalence ratios, pressures, and dissociated ratios on the ignition delay time of the methanol-syngas fuel under different conditions. The simulation was conducted based on the mechanism of MEOHSYNGAS1.0 and the results are compared with experiments. The experimental results refer to the data from both this study and the literature.

\section{Effect of the Equivalence Ratio}

The effects of different equivalence ratios on the ignition delay times of methanol and dissociated methanol gas are investigated. According to Figure 7, the equivalence ratio does not have a significant effect on the activation energy. The symbols represent the experimental data from Burke et al. (2016). The experimental results show that the increase in the equivalence ratio reduces the ignition delay time of methanol at $0.5-1.0$ equivalence ratio, 950-1450 K, 20 atm, and $\mathrm{N}_{2}=0.8$. The simulation results also show this trend and fit well with the experimental data.

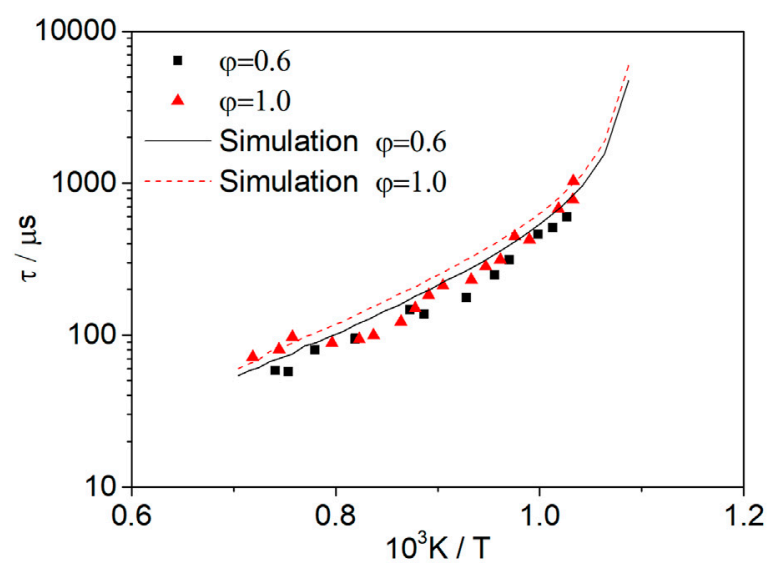

FIGURE 8 | Ignition delay times measured at $\varphi=1.0$ (Mixture 4) and $\varphi=0.6$ (Mixture 5) for dissociated methanol gas $\left(67 \% \mathrm{H}_{2} / 33 \% \mathrm{CO}\right)$ at $1.6 \mathrm{~atm}$.

The concentration of methanol is higher with the increase in the equivalence ratio. There is a higher probability of collisions among the molecules and radicals, and the heat release is faster, which further promotes the reaction of methanol with oxygen molecules and radicals, and the shortening of the ignition delay time.

Figure 8 shows the ignition delay times measured at $\varphi=1.0$ (Mixture 4) and $\varphi=0.6$ (Mixture 5) for dissociated methanol gas $\left(67 \% \mathrm{H}_{2} / 33 \% \mathrm{CO}\right)$. When the pressure is $1.6 \mathrm{~atm}$, the equivalence ratio range is $0.6-1.0$ and the temperature range is $950-1450 \mathrm{~K}$, and the equivalence ratio has little effect on the activation energy in this range. However, when the temperature is below $950 \mathrm{~K}$, there is a significant change in the slope, since the dominant reaction in the $\mathrm{H}_{2}-\mathrm{O}_{2}$ system is not the same at high and low temperatures (Kéromnès et al., 2013).

The measured ignition delay time is slightly shorter than the simulation, which is consistent with the phenomenon that an increase in the equivalence ratio can increase the ignition delay time, as shown by the simulation. For dissociated methanol gas, the ignition delay time increases with the increase in the equivalence ratio in the certain temperature and pressure range, which is significantly different from methanol fuel (Figure 7). The reason for this phenomenon is explained through a sensitivity analysis of the ignition delay time.

Figure 9 shows the normalized sensitivity coefficients of each elementary reaction in the oxidation process of dissociated methanol gas fuel at $p=1.6 \mathrm{~atm}, \varphi=1.0, \mathrm{Ar}=0.9$, and a temperature of 950,1050 , and $1300 \mathrm{~K}$, respectively. The pressure, equivalence ratio, and fuel are the same as those for Mixture 4. At $950 \mathrm{~K}$, only the elementary reaction $\mathrm{R} 5 \mathrm{O}_{2}+\mathrm{H}=\mathrm{O}+\mathrm{OH}$ has a significant effect on the ignition delay time, whereas the other elementary reactions have a negligible effect. When the temperature reaches $1050 \mathrm{~K}$, the elementary reaction R2 $\mathrm{H}_{2}+\mathrm{O}=\mathrm{H}+\mathrm{OH}$ and $\mathrm{R} 3 \mathrm{H}_{2}+\mathrm{OH}=\mathrm{H}+\mathrm{H}_{2} \mathrm{O}$ also begins to have an influence. When the temperature rises to $1300 \mathrm{~K}$, the elementary reaction $\mathrm{R}_{5} \mathrm{O}_{2}+\mathrm{H}=\mathrm{O}+\mathrm{OH}$ is still dominant, though other elementary reactions, such as $\mathrm{R}_{2} \mathrm{H}_{2}+\mathrm{O}=\mathrm{H}+\mathrm{OH}$, R6 $\mathrm{H}+$ $\mathrm{OH}+\mathrm{M}=\mathrm{H}_{2} \mathrm{O}+\mathrm{M}$, R8 O $+\mathrm{H}+\mathrm{M}=\mathrm{OH}+\mathrm{M}$, and $\mathrm{R} 24 \mathrm{CO}+$ 


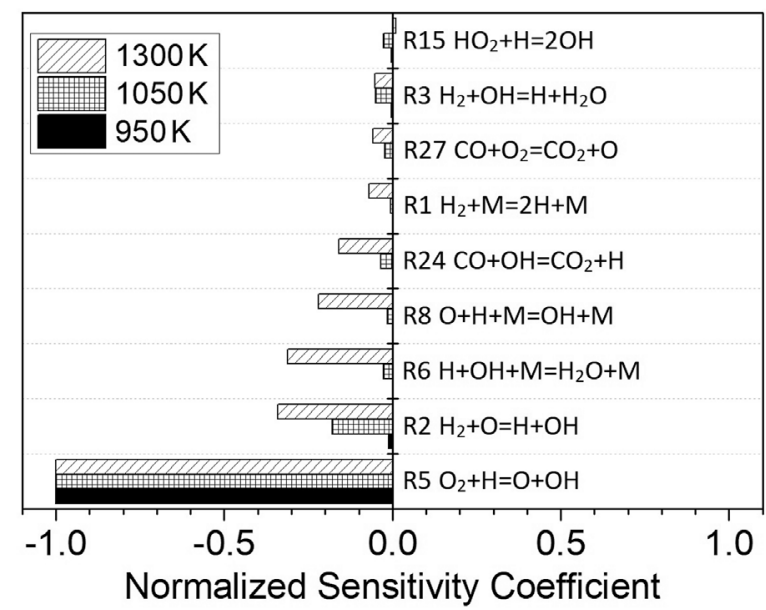

FIGURE 9 | Sensitivity analysis for dissociated methanol gas $\left(67 \% \mathrm{H}_{2}\right.$ ) $33 \% \mathrm{CO}$ ) at different temperatures; $p=1.6 \mathrm{~atm}, \varphi=1.0$, and $\mathrm{Ar}=0.9$.

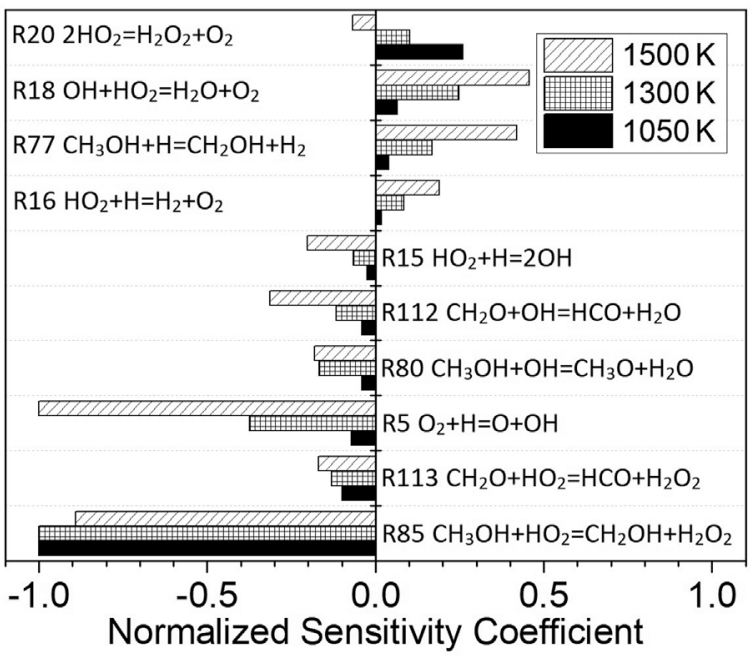

FIGURE 10 | Sensitivity analysis for methanol fuel at different temperatures; $p=1.6 \mathrm{~atm}, \varphi=1.0$, and $\mathrm{Ar}=0.9$.

$\mathrm{OH}=\mathrm{CO}_{2}+\mathrm{H}$, begin to play important roles. The reaction rate of R5 $\mathrm{O}_{2}+\mathrm{H}=\mathrm{O}+\mathrm{OH}, \mathrm{R} 2 \mathrm{H}_{2}+\mathrm{O}=\mathrm{H}+\mathrm{OH}$, and $\mathrm{R} 3 \mathrm{H}_{2}+\mathrm{OH}=\mathrm{H}+$ $\mathrm{H}_{2} \mathrm{O}$ will increase with the increase in the temperature; thus, the ignition process will be accelerated, and the ignition delay time will be shortened. The change in the sensitivity coefficient of the elementary reaction shows that the increase in the temperature not only accelerates the reaction rate, but also changes the relative importance of the elementary reaction in the ignition process and alters the reaction path of the fuel.

From 950 to $1300 \mathrm{~K}$, the reaction that promotes oxidation the most and shortens the ignition delay time is $\mathrm{R} 5 \mathrm{O}_{2}+\mathrm{H}=\mathrm{O}+\mathrm{OH}$. When the equivalence ratio of dissociated methanol gas increases, the oxygen concentration will decrease; hence, the reaction rate of

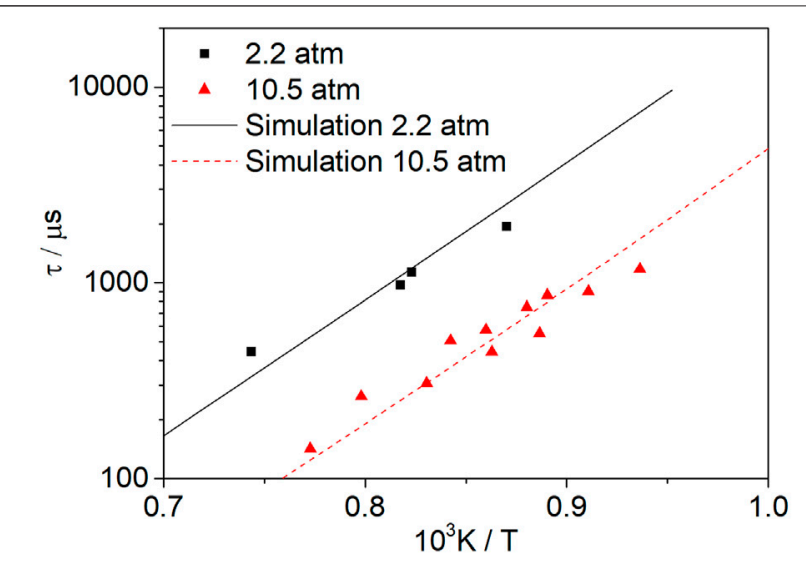

FIGURE 11 | Influence of pressure on mixtures of methanol at an equivalence ratio of 1.0. The symbols represent the experimental data from Noorani et al. (2010).

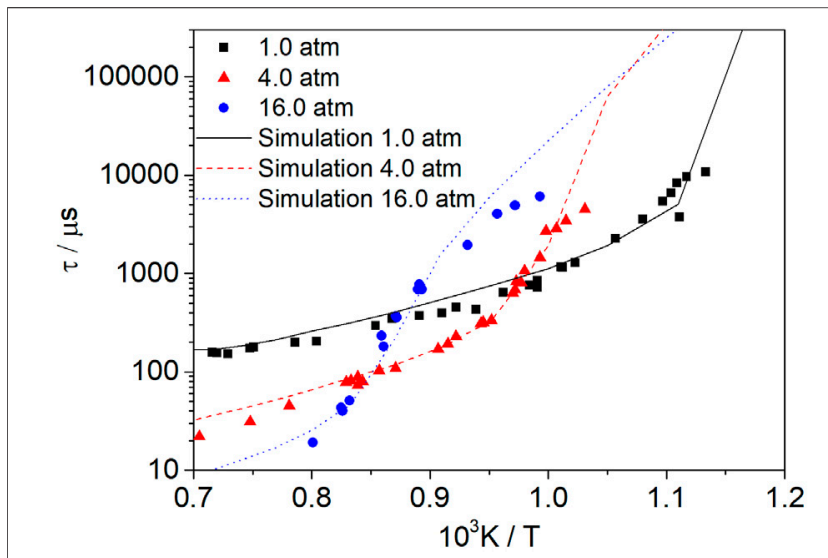

FIGURE 12 | Influence of pressure on mixtures of syngas $\left(50 \% \mathrm{H}_{2} / 50 \%\right.$ $\mathrm{CO})$ at an equivalence ratio of 1.0. The symbols represent the experimental data from Kéromnès et al. (2013).

$\mathrm{R} 5 \mathrm{O}_{2}+\mathrm{H}=\mathrm{O}+\mathrm{OH}$ will also decrease, and, as a result, the ignition delay time will increase.

Figure 10 shows the normalized sensitivity coefficients of the elementary reactions in the ignition process of methanol at $p=1.6 \mathrm{~atm}, \varphi=1.0, \mathrm{Ar}=0.9$, and temperatures of 1050, 1300 , and $1500 \mathrm{~K}$, respectively. The pressure, equivalence ratio, and fuel are the same as Mixture 1. The most important elementary reaction in the ignition process changes with the increase in temperature. At 1050 and $1300 \mathrm{~K}$, the elementary reaction $\mathrm{R} 85$ $\mathrm{CH}_{3} \mathrm{OH}+\mathrm{HO}_{2}=\mathrm{CH}_{2} \mathrm{OH}+\mathrm{H}_{2} \mathrm{O}_{2}$ is the most sensitive elementary reaction. At $1500 \mathrm{~K}$, the reaction $\mathrm{R}_{5} \mathrm{O}_{2}+\mathrm{H}=\mathrm{O}+\mathrm{OH}$ becomes the most significant, and though the reaction $\mathrm{R} 85 \mathrm{CH}_{3} \mathrm{OH}+\mathrm{HO}_{2}=$ $\mathrm{CH}_{2} \mathrm{OH}+\mathrm{H}_{2} \mathrm{O}_{2}$ still occupies an important position.

From 1050 to $1500 \mathrm{~K}, \mathrm{R} 85 \mathrm{CH}_{3} \mathrm{OH}+\mathrm{HO}_{2}=\mathrm{CH}_{2} \mathrm{OH}+\mathrm{H}_{2} \mathrm{O}_{2}$ plays a dominant role in the ignition process. Therefore, the decrease in the methanol equivalence ratio will decrease the $\mathrm{CH}_{3} \mathrm{OH}$ concentration. Consequently, this will decrease the reaction rate of $\mathrm{R} 85 \mathrm{CH}_{3} \mathrm{OH}+\mathrm{HO}_{2}=\mathrm{CH}_{2} \mathrm{OH}+\mathrm{H}_{2} \mathrm{O}_{2}$ and 


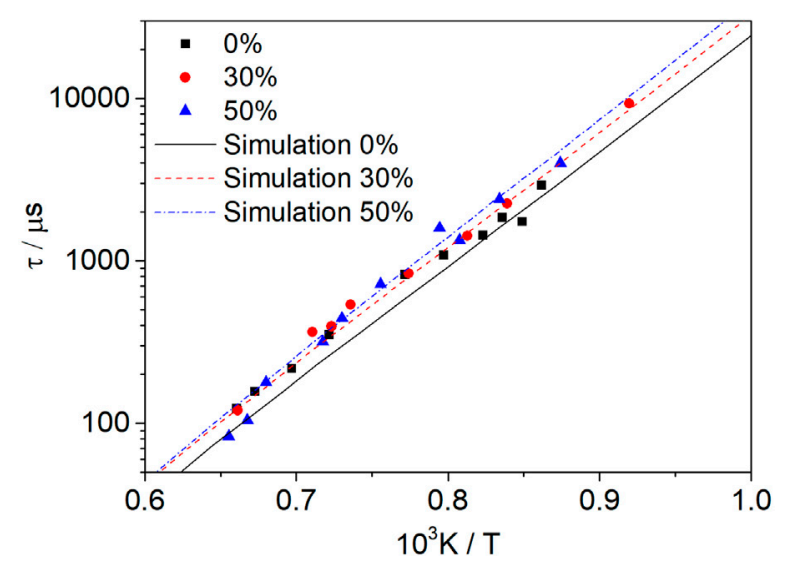

FIGURE 13 | Influence of the dissociated methanol ratio (0, 30, and 50\%) on methanol-syngas mixtures at an equivalence ratio of 1.0 and a pressure of $1.6 \mathrm{~atm}$.

ultimately increase the ignition delay time. Thus, the fuel equivalence ratio has different effects on methanol and dissociated methanol gas.

\section{Effect of the Pressure}

Figure 11 shows the change in the methanol ignition delay time with temperature at $\varphi=1.0, \mathrm{Ar}=0.92$, and pressures of 2.2 and $10.5 \mathrm{~atm}$. The symbols represent the experimental data from Noorani et al. (2010). When the pressure is increased from 2.2 to $10.5 \mathrm{~atm}$, the ignition delay time is shortened because the increase in pressure leads to higher concentrations of molecules and radicals; thus, the reaction rate is increased, resulting in a shorter ignition delay time. The experimental results show that increasing the pressure can shorten the ignition delay time.

Figure 12 shows the change of the syngas ignition delay time with temperature at $\varphi=0.5, \mathrm{Ar}=0.93$, and pressures of $1.0 \mathrm{~atm}$, $4.0 \mathrm{~atm}$, and $16.0 \mathrm{~atm}$. The symbols represent the experimental data from Kéromnès et al. (2013). The variation of the ignition delay time with temperature at different pressures is predicted well with the present model. The ignition delay time is shortened with the increase in pressure at high temperature, whereas this is not the case at low temperature.

According to literature (Konnov, 2008; Hong et al., 2011), at low pressures, oxidation is mainly controlled by the competition between $\mathrm{R} 22 \mathrm{H}+\mathrm{O}_{2}(+\mathrm{M})=\mathrm{HO}_{2}(+\mathrm{M})$ and $\mathrm{R} 5 \mathrm{O}_{2}+\mathrm{H}=\mathrm{O}+\mathrm{OH}$. At high pressures, the reaction is mainly controlled by R9 $\mathrm{H}_{2} \mathrm{O}_{2}(+\mathrm{M})=2 \mathrm{OH}(+\mathrm{M})$, and $\mathrm{R} 11 \mathrm{H}_{2} \mathrm{O}_{2}+\mathrm{H}=\mathrm{H}_{2}+\mathrm{HO}_{2}$. As the activation energy at high pressure differs from that at low pressure, the shapes of the three curves are different. In the hightemperature range, the dominant chain-branching reaction R5 $\mathrm{O}_{2}+\mathrm{H}=\mathrm{O}+\mathrm{OH}$ is not a pressure-dependent reaction. Thus, a pressure increase can increase the concentrations of radicals and decrease the ignition delay time. In the low-temperature range, it is the pressure-dependent reaction $\mathrm{R} 22 \mathrm{H}+\mathrm{O}_{2}(+\mathrm{M})=\mathrm{HO}_{2}(+\mathrm{M})$ instead of $\mathrm{R}_{5} \mathrm{O}_{2}+\mathrm{H}=\mathrm{O}+\mathrm{OH}$ that plays an important role in the reactivity. Hence, the influence of the temperature and pressure is complicated in the low-temperature range.

\section{Effect of the Dissociated Ratio}

Figure 13 shows the effect of the dissociated methanol ratio on the ignition delay time of methanol-syngas fuel at $p=1.6 \mathrm{~atm}$, $\varphi=1.0, \mathrm{Ar}=0.9$, and dissociated methanol ratios of $0 \%$ (Mixture 1), $30 \%$ (Mixture 2), and 50\% (Mixture 3). With the increase in the dissociated ratio, the ignition delay time of the mixture fuel increases, and this effect is more obvious at the low-temperature range; however, with the increase in the temperature, this effect is weakened. Regarding the experimental data, the ignition delay time can even be shortened if the dissociated methanol gas is mixed at a high-temperature range. This can be explained by sensitivity analysis.

According to the sensitivity analysis in Figure 14, similar to pure methanol, the most important reaction for the mixture fuel at 1050 and $1300 \mathrm{~K}$ is $\mathrm{R} 85 \mathrm{CH}_{3} \mathrm{OH}+\mathrm{HO}_{2}=\mathrm{CH}_{2} \mathrm{OH}+\mathrm{H}_{2} \mathrm{O}_{2}$, and at $1500 \mathrm{~K}$ it is $\mathrm{R} 5 \mathrm{O}_{2}+\mathrm{H}=\mathrm{O}+\mathrm{OH}$. However, due to the presence of $\mathrm{H}_{2}$ in the mixture, $\mathrm{H}_{2}$-related elementary reactions, such as R3 $\mathrm{H}_{2}+\mathrm{OH}=\mathrm{H}+\mathrm{H}_{2} \mathrm{O}$ and $\mathrm{R} 77 \mathrm{CH}_{3} \mathrm{OH}+\mathrm{H}=\mathrm{CH}_{2} \mathrm{OH}+\mathrm{H}_{2}$, begin to play a more important role in the oxidation process. The influence of $\mathrm{CO}$ is relatively small, mainly including the elementary reaction $\mathrm{R} 119 \mathrm{HCO}+\mathrm{M}=\mathrm{H}+\mathrm{CO}+\mathrm{M}$.

The reaction with the greatest influence on the ignition delay time at low temperature is $\mathrm{R} 85 \mathrm{CH}_{3} \mathrm{OH}+\mathrm{HO}_{2}=$ $\mathrm{CH}_{2} \mathrm{OH}+\mathrm{H}_{2} \mathrm{O}_{2}$. The concentration of $\mathrm{CH}_{3} \mathrm{OH}$ will be decreased by mixing with dissociated methanol gas, so the reaction rate will decrease, and the ignition delay time will be prolonged. With the increase in the temperature, the importance of the $\mathrm{R} 5 \mathrm{O}_{2}+\mathrm{H}=\mathrm{O}+\mathrm{OH}$ reaction increases, and so the effect of increasing the ignition delay time is not so obvious. In addition, the sensitivity coefficient of the reaction R77 $\mathrm{CH}_{3} \mathrm{OH}+\mathrm{H}=\mathrm{CH}_{2} \mathrm{OH}+\mathrm{H}_{2}$ becomes higher, and this reaction increases the ignition delay time. The addition of hydrogen inhibits the $\mathrm{R} 77 \mathrm{CH}_{3} \mathrm{OH}+\mathrm{H}=\mathrm{CH}_{2} \mathrm{OH}+\mathrm{H}_{2}$ reaction and, therefore, shortens the ignition delay time. This is the reason why the influence of blending-

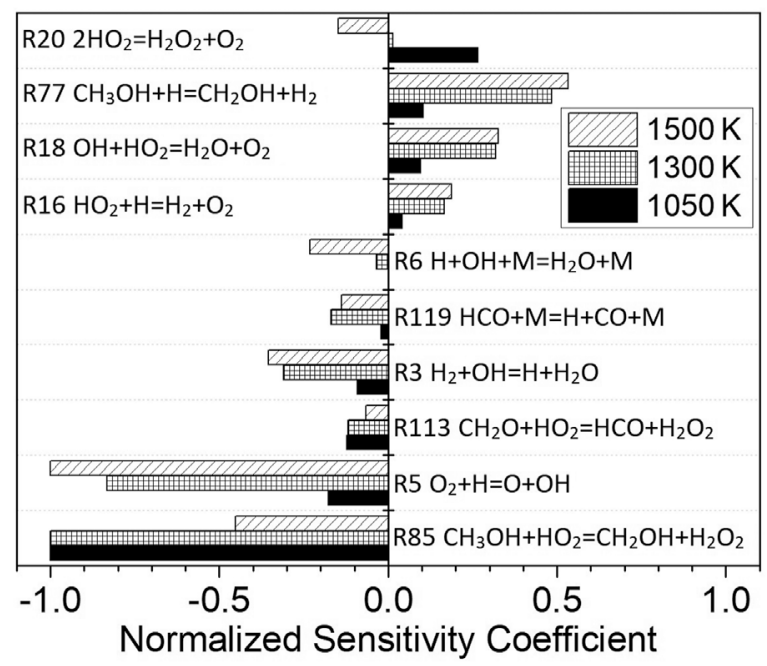

FIGURE 14 | Sensitivity analysis for different temperatures at a dissociated methanol ratio of $30 \%, p=1.6 \mathrm{~atm}$, and $\varphi=1.0$. 
dissociated methanol gas is different at high and low temperatures.

\section{CONCLUSION}

Using the exhaust heat of the internal combustion engine to dissociate methanol to produce dissociated methanol gas, and sending it into the cylinder to be blended with methanol for combustion is a promising energy utilization method. This research investigated the combustion characteristics and kinetic model of the methanol-syngas fuel and the main conclusions are as follows.

1) The ignition delay time of dissociated methanol gas with a $\mathrm{H}_{2}$ to $\mathrm{CO}$ ratio of 2:1 at equivalence ratios of 0.6 and 1.0 was measured with a shock tube. The ignition delay time of the methanol-syngas fuel with a dissociated ratio of 0,30 , and $50 \%$ was measured.

2) By analyzing the oxidation path of the fuel and the concentration change of species, the mechanism MEOHSYNGAS1.0 for the methanol-syngas fuel is proposed based on the reduction of the detailed chemical kinetic model (Mech15.34). Its working condition range covers a temperature of $800-1650 \mathrm{~K}$, a pressure of 1-50 atm, an equivalence ratio of $0.5-2.0$, and a dissociated ratio of $0-50 \%$.

3) The effect of the equivalence ratio on the ignition delay time of methanol and the dissociated methanol gas was studied. Over a certain range, the ignition delay time of methanol is decreased with the increase in the equivalence ratio, while the ignition delay time of dissociated methanol gas is increased. This is due to the difference between the elementary reaction influencing the ignition delay time of methanol and the elementary reaction influencing the ignition delay time of dissociated methanol gas.

4) The ignition delay time of methanol decreases with the increase in the pressure, due to the collision frequency between reactants increasing with the increase in pressure. For the dissociated methanol gas the relationship between the

\section{REFERENCES}

Borisut, P., and Nuchitprasittichai, A. (2019). Methanol Production via CO2 Hydrogenation: Sensitivity Analysis and Simulation-Based Optimization. Front. Energ. Res. 7, 1-10. doi:10.3389/fenrg.2019.00081

Burke, U., Metcalfe, W. K., Burke, S. M., Heufer, K. A., Dagaut, P., and Curran, H. J. (2016). A Detailed Chemical Kinetic Modeling, Ignition Delay Time and Jet-Stirred Reactor Study of Methanol Oxidation. Combustion and Flame 165, 125-136. doi:10.1016/ j.combustflame.2015.11.004

Christensen, M., Nilsson, E. J. K., and Konnov, A. A. (2016). A Systematically Updated Detailed Kinetic Model for $\mathrm{CH} 2 \mathrm{O}$ and $\mathrm{CH} 3 \mathrm{OH}$ Combustion. Energy Fuels 30, 6709-6726. doi:10.1021/acs.energyfuels.6b00049

Gong, C., Li, Z., Chen, Y., Liu, J., Liu, F., and Han, Y. (2019). Influence of Ignition Timing on Combustion and Emissions of a Spark-Ignition Methanol Engine with Added Hydrogen under Lean-Burn Conditions. Fuel 235, 227-238. doi:10.1016/j.fuel.2018.07.097 ignition delay time and pressure is complex, because the elementary reaction that has the biggest influence on the ignition delay time is different at low pressure and high pressure.

5) Through simulations and experiments, the effect of blending syngas into methanol on the ignition delay time was studied when the dissociated ratio was not greater than $50 \%$. The ignition delay time increases with the increase in the dissociated ratio, which is more obvious at the low temperature range, but the effect decreases with the increase in temperature.

\section{DATA AVAILABILITY STATEMENT}

The original contributions presented in the study are included in the article/Supplementary Material, further inquiries can be directed to the corresponding author.

\section{AUTHOR CONTRIBUTIONS}

YC: conceptualization, investigation, writing-original draft; YJ: funding acquisition, writing-review and editing; XW: investigation; HL: supervision, writing-review and editing.

\section{FUNDING}

This work was supported by the Department of Science and Technology of Hubei Province, China (Grant numbers 2016AAA045 and 2020BAB127).

\section{SUPPLEMENTARY MATERIAL}

The Supplementary Material for this article can be found online at: https:/www.frontiersin.org/articles/10.3389/fenrg.2021.812522/ full\#supplementary-material

Held, T. J., and Dryer, F. L. (1998). A Comprehensive Mechanism for Methanol Oxidation. Int. J. Chem. Kinet. 30, 805-830. doi:10.1002/(sici)1097-4601(1998) 30:11<805:aid-kin4>3.0.co;2-z

Hong, Z., Davidson, D. F., and Hanson, R. K. (2011). An Improved H2/O2 Mechanism Based on Recent Shock Tube/laser Absorption Measurements. Combustion and Flame 158, 633-644. doi:10.1016/j.combustflame.2010.10.002

Jaimes, D., McDonell, V. G., and Samuelsen, G. S. (2018). Lean Flammability Limits of Syngas/Air Mixtures at Elevated Temperatures and Pressures. Energy Fuels 32, 10964-10973. doi:10.1021/acs.energyfuels.8b02031

Jaspers, B. C., Kuo, P.-C., Amladi, A., van Neerbos, W., and Aravind, P. V. (2021). Negative CO2 Emissions for Transportation. Front. Energ. Res. 9, 1-5. doi:10.3389/fenrg.2021.626538

Ji, C., Dai, X., Wang, S., Liang, C., Ju, B., and Liu, X. (2013). Experimental Study on Combustion and Emissions Performance of a Hybrid Syngas-Gasoline Engine. Int. J. Hydrogen Energ. 38, 11169-11173. doi:10.1016/ j.ijhydene.2013.02.101

Jiang, Y., Mei, Z., and Wang, R. (2019). Study on Combustion Characteristics of Gasoline Engine Blending with Dissociated Methanol. Huazhong Keji Daxue 
Xuebao (Ziran Kexue Ban)/journal Huazhong Univ. Sci. Technol. (Natural Sci. Ed.) 47, 1-6. doi:10.13245/j.hust.190901

Kalitan, D. M., Mertens, J. D., Crofton, M. W., and Petersen, E. L. (2007). Ignition and Oxidation of Lean $\mathrm{CO} / \mathrm{H} 2$ Fuel Blends in Air. J. Propulsion Power 23, 1291-1301. doi:10.2514/1.28123

Kéromnès, A., Metcalfe, W. K., Heufer, K. A., Donohoe, N., Das, A. K., Sung, C.J., et al. (2013). An Experimental and Detailed Chemical Kinetic Modeling Study of Hydrogen and Syngas Mixture Oxidation at Elevated Pressures. Combustion and Flame 160, 995-1011. doi:10.1016/ j.combustflame.2013.01.001

Konnov, A. A. (2009). Implementation of the NCN Pathway of Prompt-NO Formation in the Detailed Reaction Mechanism. Combustion and Flame 156, 2093-2105. doi:10.1016/j.combustflame.2009.03.016

Konnov, A. A. (2008). Remaining Uncertainties in the Kinetic Mechanism of Hydrogen Combustion. Combustion and Flame 152, 507-528. doi:10.1016/ j.combustflame.2007.10.024

Li, J., Zhao, Z., Kazakov, A., Chaos, M., Dryer, F. L., and Scire, J. J. (2007). A Comprehensive Kinetic Mechanism for $\mathrm{CO}, \mathrm{CH} 2 \mathrm{O}$, and $\mathrm{CH} 3 \mathrm{OH}$ Combustion. Int. J. Chem. Kinet. 39, 109-136. doi:10.1002/kin.20218

Li, R., Wang, Z., Tang, C., and Meng, X. (2021). Study on Particulate Structure Characteristics of Diesel Engines Fueled with a Methanol/Biodiesel Blend. ACS Omega 6, 6081-6087. doi:10.1021/acsomega.0c04371

Liao, S.-Y., Li, H.-M., Mi, L., Shi, X.-H., Wang, G., Cheng, Q., et al. (2011). Development and Validation of a Reduced Chemical Kinetic Model for Methanol Oxidation. Energy Fuels 25, 60-71. doi:10.1021/ef101335q

Liu, J., and Dumitrescu, C. E. (2019). Numerical Investigation of Methane Number and Wobbe Index Effects in Lean-Burn Natural Gas Spark-Ignition Combustion. Energy Fuels 33, 4564-4574. doi:10.1021/acs.energyfuels.8b04463

Liu, Y., Cheng, J., Zou, C., Lu, L., and Jing, H. (2019). Ignition Delay Times of Ethane under O2/CO2 Atmosphere at Different Pressures by Shock Tube and Simulation Methods. Combustion and Flame 204, 380-390. doi:10.1016/ j.combustflame.2019.03.031

Mansfield, A. B., and Wooldridge, M. S. (2014). High-pressure Low-Temperature Ignition Behavior of Syngas Mixtures. Combustion and Flame 161, 2242-2251. doi:10.1016/j.combustflame.2014.03.001

Moley, C. (2003). GASEQ A Chemical Equilibrium Program for Windows. Version $0.7912,1-2$. Available at: http://www.gaseq.co.uk/.

Nguyen, D.-K., and Verhelst, S. (2017). Computational Study of the Laminar Reaction Front Properties of Diluted Methanol-Air Flames Enriched by the Fuel Reforming Product. Energy Fuels 31, 9991-10002. doi:10.1021/ acs.energyfuels.7b00691

Noorani, K. E., Akih-Kumgeh, B., and Bergthorson, J. M. (2010). Comparative High Temperature Shock Tube Ignition of C1-C4 Primary Alcohols. Energy Fuels 24, 5834-5843. doi:10.1021/ef1009692

Pepiotdesjardins, P., and Pitsch, H. (2008). An Efficient Error-Propagation-Based Reduction Method for Large Chemical Kinetic Mechanisms. Combustion and Flame 154, 67-81. doi:10.1016/j.combustflame.2007.10.020

Pichler, C., and Nilsson, E. J. K. (2020). Pathway Analysis of Skeletal Kinetic Mechanisms for Small Alcohol Fuels at Engine Conditions. Fuel 275, 117956. doi:10.1016/j.fuel.2020.117956

Pichler, C., and Nilsson, E. J. K. (2018). Reduced Kinetic Mechanism for Methanol Combustion in Spark-Ignition Engines. Energy Fuels 32, 12805-12813. doi:10.1021/acs.energyfuels.8b02136

Pinzón, L. T., Mathieu, O., Mulvihill, C. R., Schoegl, I., and Petersen, E. L. (2019). Ignition Delay Time and $\mathrm{H} 2 \mathrm{O}$ Measurements during Methanol Oxidation behind Reflected Shock Waves. Combustion and Flame 203, 143-156. doi:10.1016/j.combustflame.2019.01.036
Sun, H., Yang, S. I., Jomaas, G., and Law, C. K. (2007). High-pressure Laminar Flame Speeds and Kinetic Modeling of Carbon Monoxide/hydrogen Combustion. Proc. Combustion Inst. 31, 439-446. doi:10.1016/ j.proci.2006.07.193

Thi, L. D., Zhang, Y., and Huang, Z. (2014). Shock Tube Study on Ignition Delay of Multi-Component Syngas Mixtures - Effect of Equivalence Ratio. Int. J. Hydrogen Energ. 39, 6034-6043. doi:10.1016/j.ijhydene.2014.01.170

Turányi, T. (1997). Applications of Sensitivity Analysis to Combustion Chemistry. Reliab. Eng. Syst. Saf. 57, 41-48. doi:10.1016/S0951-8320(97)00016-1

Vancoillie, J., Christensen, M., Nilsson, E. J. K., Verhelst, S., and Konnov, A. A. (2012). Temperature Dependence of the Laminar Burning Velocity of Methanol Flames. Energy Fuels 26, 1557-1564. doi:10.1021/ef2016683

Verhelst, S., Turner, J. W., Sileghem, L., and Vancoillie, J. (2019). Methanol as a Fuel for Internal Combustion Engines. Prog. Energ. Combustion Sci. 70, 43-88. doi:10.1016/j.pecs.2018.10.001

Wen, X. (2018). Study on the Ignition Characteristics of Methanol Syngas. [dissertation/master's thesis]. Wuhan: Huazhong University of Science and Technology.

Xie, M. (2016). Experimental Study on Mixed Combustion of Dissociated Methanol in SI Engine. [dissertation/master's thesis]. Wuhan: Huazhong University of Science and Technology.

Yao, C., Li, X., Zang, R., and Xu, Y. (2014). Research on the Performance of an Electronically Controlled Spark Ignition Engine Fuelled with Hydrogen-Rich Gases. Proc. Inst. Mech. Eng. D: J. Automobile Eng. 228, 1084-1094. doi:10.1177/0954407014525360

Zhang, B., Ji, C., Wang, S., and Liu, X. (2014). Combustion and Emissions Characteristics of a Spark-Ignition Engine Fueled with Hydrogen-Methanol Blends under Lean and Various Loads Conditions. Energy 74, 829-835. doi:10.1016/j.energy.2014.07.055

Zhang, J., and Zhang, Y. (2019). Reduced Mechanism Generation for MethanolBased Toluene Reference Fuel with Combined Reduction Methods. Fuel 247, 135-147. doi:10.1016/j.fuel.2019.03.028

Zhao, T., Zhang, J., Ju, D., Huang, Z., and Han, D. (2019). Exergy Losses in Premixed Flames of Dimethyl Ether and Hydrogen Blends. Front. Energ. 13, 658-666. doi:10.1007/s11708-019-0645-8

Zhou, C.-W., Li, Y., Burke, U., Banyon, C., Somers, K. P., Ding, S., et al. (2018). An Experimental and Chemical Kinetic Modeling Study of 1,3-butadiene Combustion: Ignition Delay Time and Laminar Flame Speed Measurements. Combustion and Flame 197, 423-438. doi:10.1016/j.combustflame.2018.08.006

Conflict of Interest: The authors declare that the research was conducted in the absence of any commercial or financial relationships that could be construed as a potential conflict of interest.

Publisher's Note: All claims expressed in this article are solely those of the authors and do not necessarily represent those of their affiliated organizations, or those of the publisher, the editors, and the reviewers. Any product that may be evaluated in this article, or claim that may be made by its manufacturer, is not guaranteed or endorsed by the publisher.

Copyright (c) 2022 Chen, Jiang, Wen and Liu. This is an open-access article distributed under the terms of the Creative Commons Attribution License (CC $B Y)$. The use, distribution or reproduction in other forums is permitted, provided the original author(s) and the copyright owner(s) are credited and that the original publication in this journal is cited, in accordance with accepted academic practice. No use, distribution or reproduction is permitted which does not comply with these terms. 